\title{
A Flipped Classroom Designed for the Teaching of "Network Equipment Configuration and Management"
}

\author{
Fang Hu*, Xiao Cai, Xinyu Zhang \\ Sichuan Staff University of Science and Technology, Chengdu, China \\ Email: ^hf_sc@126.com
}

How to cite this paper: Hu, F., Cai, X. and Zhang, X.Y. (2019) A Flipped Classroom Designed for the Teaching of "Network Equipment Configuration and Management". Open Journal of Social Sciences, 7, 201-208. https://doi.org/10.4236/jss.2019.75016

Received: April 28, 2019

Accepted: May 21, 2019

Published: May 24, 2019

Copyright $\odot 2019$ by author(s) and Scientific Research Publishing Inc. This work is licensed under the Creative Commons Attribution International License (CC BY 4.0).

http://creativecommons.org/licenses/by/4.0/

\begin{abstract}
To improve the teaching efficiency and quality, we have introduced the flipped classroom to the "network equipment configuration and management" course. This paper describes in detail the various stages of this teaching mode. A case in our school demonstrates that the flipped classroom which is based on micro course encourages the students to learn in a more active way and improves the teaching quality, thereby effectively solving the obstacles encountered in traditional teaching such as insufficient class hours and interaction. This teaching mode enables the course to adapt to the college students' learning characters, which are personalized and differentiated.
\end{abstract}

\section{Keywords}

Flipped Classroom, Microlecture

\section{Introduction}

\subsection{Course Information}

"Network equipment configuration and management" is a core course for students who major in computer network technology in our school. The class arrangement is quite tight due to plenty of course key points which including the common network equipment introduction, the concept and working principle, the basic and advanced configuration (such as VLAN partition, ACL, NAT, RIP, OSPF, etc.), daily management and maintenance. Students are required to be able to master each key point and manage equipment independently.

\subsection{Students Information}

We selected 40 students majoring in network technology from the department of 
information engineering to participate in the flipped classroom. All students come from Tibet. They are eager to learn, polite, good at singing and dancing, adept at practical ability, but they lack a solid knowledge structure, and therefore have difficulty grasping the essence of course, not to mention applying the learned knowledge [1]. These students are less likely to use online courses for independent learning, and lack necessary information technology capability. Good information technology understanding, learning ability and advanced critical thinking can be cultivated using the flipped classroom.

\section{Concepts}

\subsection{The Flipped Classroom}

A flipped classroom is an instructional strategy and a type of blended learning that reverses the traditional learning environment by delivering instructional content, often online, outside of the classroom. It moves activities, including those that may have traditionally been considered homework, into the classroom. In a flipped classroom, students watch online lectures, collaborate in online discussions, or carry out research at home while engaging in concepts in the classroom with the guidance of a mentor. The flipped classroom intentionally shifts instruction to a learner-centered model in which class time explores topics in greater depth and creates meaningful learning opportunities, while educational technologies such as online videos are used to "deliver content" outside of the classroom. In a flipped classroom, "content delivery" may take a variety of forms. Often, video lessons prepared by the teacher or third parties are used to deliver content, although online collaborative discussions, digital research, and text readings may be used. It has been shown that the ideal length of the video lesson to be is eight to twelve minutes [2] [3] [4].

\subsection{Microlecture}

The term microlecture is not used here to refer to microcontent for microlearning, but to actual instructional content that is formatted for online and mobile learning using a constructivist approach. David M. Penrose (aka the One Minute Professor), an independent instructional designer and eLearning consultant, has articulated the process for creating these microlectures. As stated by [5], these specific lectures are combined with specific activities designed to promote the epistemic engagement of the learner.

\subsection{Feasibility of This Mode}

Involved forty students have been enrolled for one semester. They are very familiar with each other and cooperate well with teachers in class. The teachers have rich teaching experience, and are adept at all kinds of teaching-auxiliary materials, which provide great help for the design and production of micro courses and the teaching practice of flipped classroom.

Considering the curriculum alone, the rich experimental case resources are 
very rich, and it is relatively easy to find a case as the object of analysis and discussion, which can provoke students' learning interest, enabling active learning of students.

\section{Preliminary Class Design}

\subsection{Class Contents}

There are abundant teaching contents in this course, and the combination of theory and practice is extraordinarily tight. In accordance with the fact that $\mathrm{Ti}$ betan students generally have a weak learning foundation, we have optimized the teaching schedule. We focus primarily on the basic working principles and configuration of switches and routers, and emphasize the common functions of switches and routers utilized in small to medium enterprises. After simplifying the teaching content, we direct the students to learn in a targeted way, making them concentrate on more practical key points and avoiding the complex contents. Cisco Packet Tracer 6.2 is used as network simulation program in experimental teaching. Cisco Packet Tracer is a powerful network simulation platform inspiring student to experiment with network behavior and ask "what if" questions. It supplements physical equipment in the classroom by allowing students to create a network with an almost unlimited number of devices, encouraging practice, discovery and troubleshooting.

\subsection{Production of Microlecture}

Easy Sketch Pro 3 is adopted as the tool to produce our microlectures. While there are many video products and services available, very few rival Easy Sketch Pro for its ease of use and "drag 'n' drop" ability to create Sketch Videos. Its features include the transition from sketch to live video intros and uploading of user's own music background as well as images. The Camtasia studio 8 is used as the screen recorder and video editor.

\subsection{Study Groups}

The scientific organization of study groups is the basis of cooperative learning. The dividing principle is that a group should contain students with distinctive and different characteristics and similarity should be observed between any two groups. After understanding each student's learning ability and personality, the teacher determines the allocation and the group leader. These students are divided into 5 groups.

\subsection{Class Design}

\subsubsection{Pre-Class Preparation}

1) Through the detailed arrangement of knowledge points involved in the module, some classic cases are screened out. According to the case background and the learning level of students, the way of explanation is clarified. We will then record some teaching videos (see Figure 1) which last 5 to 8 minutes for 


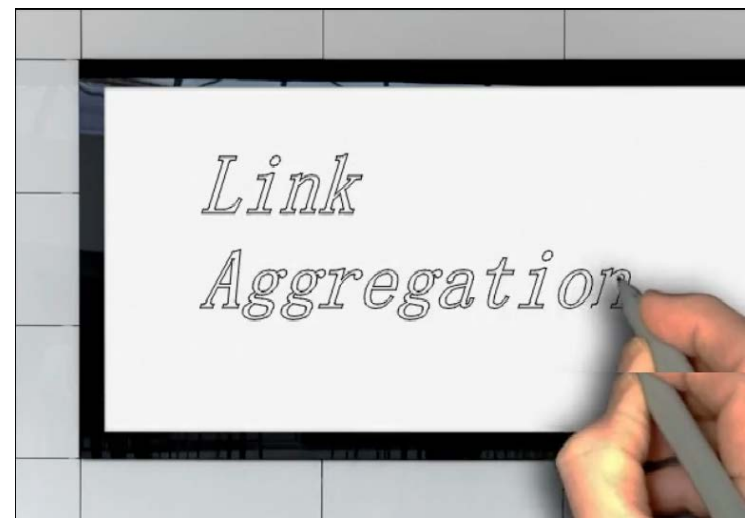

Figure 1. Videos made by easy sketch Pro 3.

each knowledge-point. The Cisco Packet Tracer is used to simulate the network environment to complete the hands-on requirements of the case, and the detailed operation is recorded on the screen (see Figure 2).

2) Study materials and documents including teaching courseware, experimental manuals, students' learning task list, test questions and auxiliary materials for students' self-learning are well prepared.

3) Design the learning tasks (for example, the link aggregation task list is shown in Table 1). The task list contains learning contents, learning objectives, knowledge points, watching teaching video (explaining video and operating video), recording difficult points, completing an experiment, completing tests and summarizing.

4) When providing students with all kinds of learning resources that they need, different difficulty levels are set for the key contents, such as basic level, advanced level, extended level, etc. When learning before class, students can look for courseware, videos and other materials suitable for their needs in the learning resource database.

\subsubsection{Self-Learning}

After receiving the assigned tasks, students can watch the teaching videos uploaded by teachers anytime and anywhere through the online teaching platform. If students have any questions, they can communicate and discuss with others in the discussion area of the online learning platform. After the completion of relevant knowledge learning, the test will be carried out on the platform, and the difficult points will be submitted to the teacher. In this stage, teachers regularly answer questions online to provide help for students. Students are encouraged to answer each other's questions, and bonus points are awarded to those who provide correct answers. At the same time, we also set up a class supervision mechanism, in which the group leader is responsible for supervising and urging the students to complete the learning tasks, and timely feedback the completion information to the teacher.

Before class activities, we ask students to complete the pre-class test questions and thinking questions. The pre-class tests emphasize the basic knowledge, and 


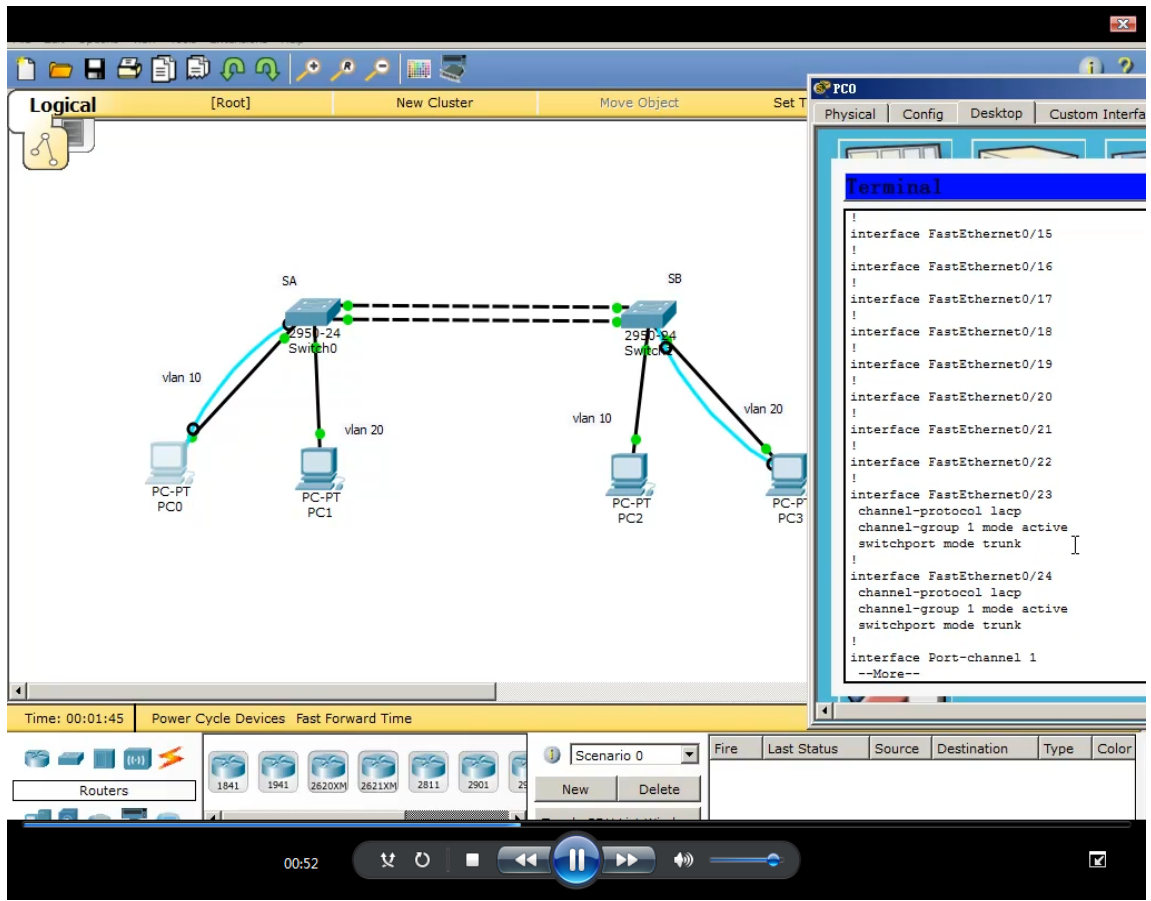

(a)

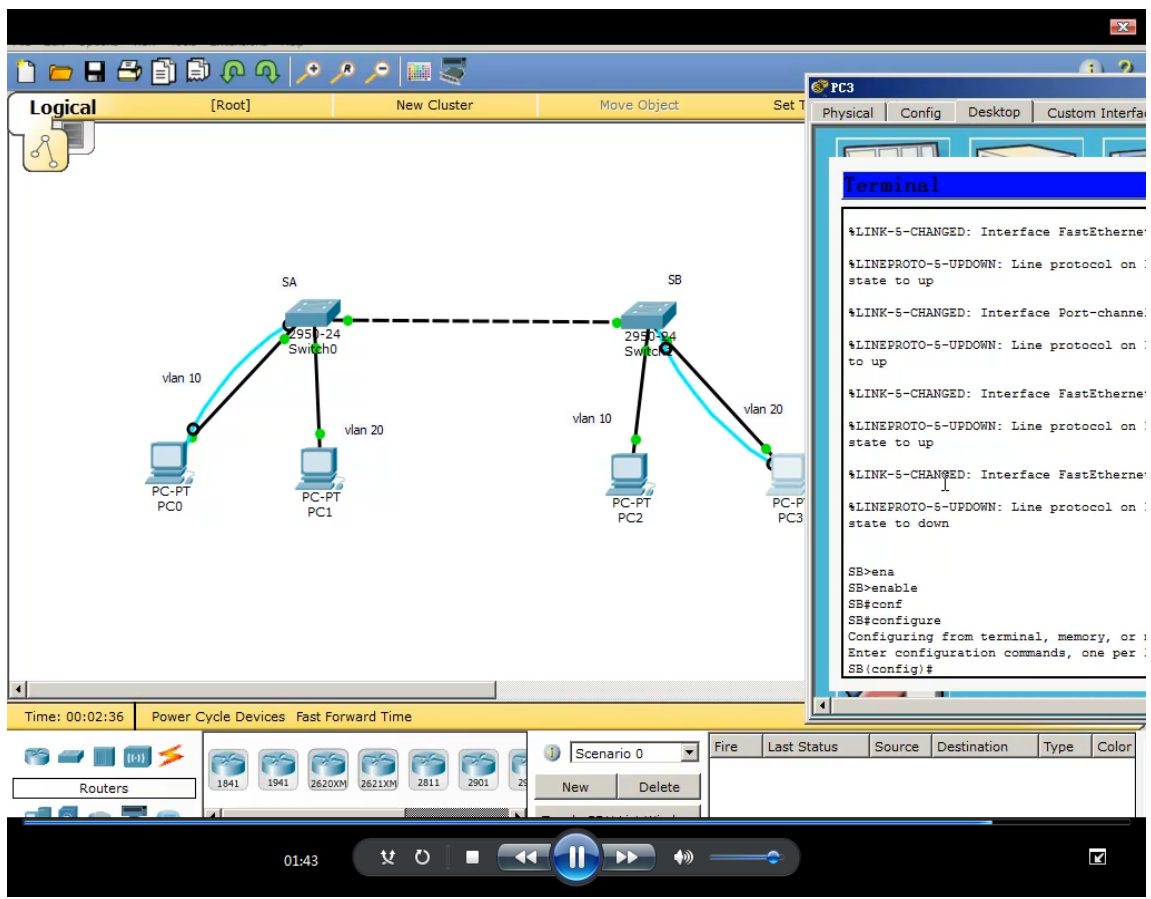

(b)

Figure 2. Videos recorded by the Camtasia studio 8 .

the purpose is for the teacher to understand the self-learning effect, thus determining the class content, avoiding students legging behind. The pre-class thinking questions are comprehensive and advanced, which serve as discussion topics in class, so that the capable students can demonstrate themselves and learn more. 
Table 1. Link aggregation task list.

\begin{tabular}{cl}
\hline \multicolumn{1}{c}{ Topic: link aggregation } \\
\hline & $\begin{array}{l}\text { Study the assigned enterprise network deployment topology and mark the key } \\
\text { node. List the potential influence factors of network. }\end{array}$ \\
Basic & $\begin{array}{l}\text { Study the materials on the platform including PPT, videos, manuals and } \\
\text { references with the emphasis on the work principle, workflow and } \\
\text { configuration of link aggregation. } \\
\text { requirements } \\
\text { Learn the application of link aggregation. } \\
\text { Master the configuration of link aggregation in Cisco and } \\
\text { HUAWEI switches. }\end{array}$ \\
Advanced & $\begin{array}{l}\text { Describe the workflow of LACP using graphs and words. } \\
\text { requirements }\end{array}$ \\
$\begin{array}{l}\text { Search the application scenarios of link aggregation based on } \\
\text { online literatures. }\end{array}$
\end{tabular}

\subsection{Class Activities}

1) Students raise questions and teachers participate in the exploration with students. First, students discuss the pre-class test in groups. The teacher integrates the difficult points recorded by the students before class, the discussion hotspots on the network platform, and the key points of the knowledge of this module, extracts the most important ones, and discusses and solves the problems together with the students.

2) Students practice under the guidance of teachers. The teacher divides the project function into several sub-tasks and assigns them to the students. Teachers are devoted to guiding students to find solutions to problems, and gradually make them think independently. In this stage, students with insufficient learning ability will be individually tutored to maximize the teaching effect, so as to ensure that students do not fall behind.

3) Students summarize the class followed by the teachers' comments. Students summarize the project function learned in the class. They may demonstrate and explain their fruits by group, sharing ideas and methods to solve problems, expanding their thinks, and promoting learning atmosphere. The teachers then deliver the conclusion remarks and explain the common faults made by beginners.

\subsection{Evaluation and Summary}

Students summarize the whole learning process, and submit their work and take after-class test, based on which teachers make a preliminary evaluation.

At the end of the course, each student will be required to deliver a presentation on the content he/she has completed and carry out the functional test. All the students will watch and grade on the spot. The final score of students is averaged by both the teacher's and other students' evaluation. This interactive evaluation method can effectively stimulate students' learning interest and creativity, and most students can seriously prepare for the presentation. 


\section{Feedback of the Flipped Classroom}

\subsection{Effect}

The implementation of flipped classroom teaching mode in the course of network equipment configuration and management has achieved a series of results. First, flipped classroom requires students to learn theoretical knowledge and complete experiments by themselves before class. Students are in a leading position in class and they are transformed from passive learning to active learning, which evokes students' enthusiasm. Second, in view of the teacher's questions and actual case studies, students need to actively discuss with team members including determine how to solve the problem and the specific solutions, which can develop the students' ability of expression, promote the sense of cooperation, cultivate critical thinking, and improve the practice ability. Third, the role of the teacher is changed to a director. In class, there is no need to explain the theory too much, and the focus is on the organization of discussions, which is conducive to the improvement of the teacher's organizational ability. Finally, this teaching mode solves the different requirements of students with different computer levels and teaches students in accordance with their aptitude to a greater extent.

\subsection{Problems}

In the process of implementing the flipped classroom teaching mode, we also meet with some potential problems. First, subjectively speaking, students generally do not have good self-study habits, and the effect of pre-class work cannot be guaranteed, so their classroom discussion is not active, which affects the effect of flipped classroom to a certain extent. On the other hand, teachers lack experience in organizing class discussions. This requires teachers to study the design and organization of classroom discussion, fully mobilizing the enthusiasm of students. Second, the form of micro courses is relatively simple, lacking of interaction, and the amount of test questions is limited. In a big class, the teacher is more difficult to organize, and some students are lazy to think, affecting the teaching effect. Third, all the teaching materials, tests, questionnaires and Q\&A feedback in this study are conducted on the school's online teaching platform. The teaching platform's self-test questions lack the support of operation questions, and the questionnaire analysis and evaluation method is relatively simple.

\section{Conclusion Remarks}

It is the mission of every educator to teach students in accordance with their aptitude, to fully mobilize students' initiative, and to improve classroom effectiveness to a greater extent. Flipped classroom which is based on micro class introduced in this paper proves that it cannot only improve the teaching effect, but also enhance students' abilities in various aspects. As a teaching mode, flipped classroom has a good effect in the course of "network equipment and management", but whether it is suitable for more courses remains to be seen. 


\section{Conflicts of Interest}

The authors declare no conflicts of interest regarding the publication of this paper.

\section{Supported}

This work is supported by the teaching reform project of Sichuan Staff University of Science and Technology (Project Number: kzd2018007).

\section{References}

[1] Wu, Y. (2012) Analysis of Examination Achievements of Tibetan "9 + 3" Students Majoring in Nursing Specialty. The Science Education Article Collects, No. 2, 141-142. (In Chinese)

[2] Cobb, W. and Wendy, N. (2016) Turning the Classroom Upside Down: Experimenting with the Flipped Classroom in American Government. Journal of Political Science Education, 12, 1-14. https://doi.org/10.1080/15512169.2015.1063437

[3] Murthy, S. and Naraharisetty, P. (2011) Investigating the Effectiveness of Non-Interactive Video-Based Lectures in e-Learning-Case Study at Master of Science in Information Technology (MSIT) Program. Journal of Neurochemistry, 61, 979-986. https://doi.org/10.1109/T4E.2011.31

[4] Herreid, C.F. and Schiller, N.A. (2013) Case Study: Case Studies and the Flipped Classroom. Journal of College Science Teaching, 42, 62-67.

[5] Mclaughlin, J.E., et al. (2014) The Flipped Classroom: A Course Redesign to Foster Learning and Engagement in a Health Professions School. Academic Medicine, 89, 236-243. https://doi.org/10.1097/ACM.0000000000000086 